\title{
PERANCANGAN MEDIA KOMUNIKASI DAN INFORMASI SEKOLAH PPPK PETRA SURABAYA DALAM BENTUK APLIKASI SMARTPHONE BERBASIS ANDROID
}

\author{
Christyan Budi Susilo ${ }^{1}$ \\ Benny Rahmawan ${ }^{1}$ \\ Robi Wigeno ${ }^{1}$ \\ Institut Informatika Indonesia, Surabaya ${ }^{l}$ \\ christyan@ikado.ac.id
}

\begin{abstract}
Abstrak
Sekolah PPPK Petra merupakan salah satu lembaga pendidikan di Surabaya. Media informasi dan komunikasi cetak yang dibagikan kepada siswa, orang tua, serta guru dan karyawan selama ini sangat jarang dibaca, bahkan yang diedarkan kepada siswa di jenjang SMP dan SMA banyak ditemukan di tempat sampah dan juga dibuat sebagai mainan pesawat kertas. Hal tersebut menjadi tidak efisien, karena dana yang dikeluarkan untuk pencetakan tidak sedikit. Metode yang dipakai dalam penelitian ini yaitu prototyping. Cara pengumpulan data yang digunakan adalah melalui wawancara mendalam, kuesioner, observasi dan survei. Selain itu juga dilakukan studi komparator dan kompetitor terhadap aplikasi sejenis. Sedangkan dalam membantu analisis dan perancangan desain User Interface menggunakan kuesioner kriteria desain. Hasil dari penelitian pada Sekolah PPPK Petra dilakukan perancangan media komunikasi dan informasi dalam bentuk aplikasi smartphone berbasis Android. Penggunaan aplikasi mobile pada Android diharapkan mampu menjadi media komunikasi bagi sekolah dan dapat menyampaikan informasi secara cepat dan mudah kepada siswa dan orangtua. Selain pembuatan aplikasi, tentunya diperlukan media untuk mempromosikan aplikasi ini agar orang-orang dapat mengetahui keberadaan aplikasi ini. Media pendukung yang digunakan untuk melakukan promosi meliputi poster, spanduk, $x$-banner dan web banner pada website PPPK Petra.
\end{abstract}

Kata kunci: Aplikasi, Android, Informasi, Komunikasi.

\begin{abstract}
PPPK Petra School is one of the educational institutions in Surabaya. Media information and printed communications distributed to students, parents, as well as teachers and employees have been rarely read, even those distributed to students in junior and senior high school are found
\end{abstract}


in trash and also made as toys. It becomes inefficient, because the cost spent on printing are quite high. The method used in this research is prototyping. Data collection methods used are through in-depth interviews, questionnaires, observations and surveys. In addition, comparator and competitor studies on similar applications are also conducted. While in assisting analysis and design of User Interface design using design criteria questionnaire. The results of research on PPPK Petra School conducted the design of communication media and information in the form of Androidbased smartphone applications. The use of mobile applications on android is expected to be a medium of communication for schools and can convey information quickly and easily to students and parents. In addition to making the application, of course, the media needed to promote this application so that people can find out the existence of this application. Supporting media used for promotion include posters, banners, $x$-banner and web banner on PPPK Petra website.

Keywords: Application, Android, Information, Communication.

\section{PENDAHULUAN}

Perkembangan ilmu pengetahuan dan teknologi telah mengalami kemajuan yang sangat pesat. Keterkaitan manusia dengan teknologi pada saat ini sangatlah erat, teknologi hadir hampir di semua lini kehidupan manusia. Penggunaan teknologi sebagai media komunikasi dan informasi, belajar, permainan, bisnis merupakan hal yang sudah tidak asing lagi di telinga kita.

Kemajuan teknologi juga menjadi faktor pendukung pada pendidikan yang membuat segala sesuatunya menjadi lebih lancar dan mudah. Internet, wifi, dan komputer dapat menjadi penunjang kemajuan pada pendidikan yang dapat digunakan sebagai media mencari maupun penyampaian informasi. Dunia pendidikan dituntut untuk terus-menerus mengikuti alur perkembangan ilmu dan teknologi yang kian berkembang pesat. Perkembangan mobile device semakin hari semakin maju pesat dengan kecanggihan dan kelengkapan fitur-fitur yang disajikan secara up to date sehingga dapat memudahkan seseorang dalam mengakses informasi kapan saja dan di mana saja. Pemanfaatan mobile device dalam dunia pendidikan juga banyak digunakan untuk memudahkan dalam penyampaian dan pengaksesan informasi melalui gadget/smartphone. 
Sekolah PPPK Petra merupakan salah satu lembaga pendidikan di Surabaya, memiliki siswa yang rata-rata menggunakan smartphone untuk menunjang proses belajarnya dibandingkan menggunakan PC atau notebook. Menurut data yang diperoleh dari Sekolah PPPK Petra, lebih dari 50\% siswa di jenjang SMA menggunakan smartphone selama 6-8 jam dalam sehari.

Selama ini, media komunikasi dan informasi yang dimiliki sekolah PPPK Petra berupa buletin bulanan yang memuat kegiatan-kegiatan di sekolah dan prestasi siswa yang hanya diedarkan di kalangan siswa, serta tabloid yang dikhususkan untuk kalangan guru dan karyawan. Media komunikasi yang disebarkan kepada siswa, orang tua, serta guru dan karyawan sangat jarang dibaca, kebanyakan hanya ditaruh setelah menerima buletin atau tabloid tersebut. Bahkan yang diedarkan kepada siswa di jenjang SMP dan SMA banyak ditemukan di tempat sampah dan juga dibuat sebagai mainan pesawat kertas.

Berdasarkan hasil penelitian yang dilakukan, dapat disimpulkan beberapa hal berikut: 1) Siswa malas membawa media komunikasi berupa buletin yang dibagikan setiap bulan; 2) Media komunikasi cetak sekarang kurang efektif, karena dana yang dikeluarkan untuk percetakan tidak sedikit; 3) Penyampaian informasi sekolah kepada siswa dan orangtua kurang cepat dan mudah.

Penggunaan aplikasi mobile pada Android diharapkan mampu menjadi media komunikasi bagi sekolah PPPK Petra dan dapat menyampaikan informasi secara cepat dan mudah kepada siswa dan orangtua. Selain itu juga mampu mendukung program pengurangan penggunaan kertas (paperless) yang sedang dilakukan oleh sekolah PPPK Petra.

\section{KAJIAN TEORI}

\section{Teori Aplikasi}

Menurut Sutabri (2012:147), Aplikasi adalah alat terapan yang difungsikan secara khusus dan terpadu sesuai kemampuan yang dimilikinya. Sedangkan menurut Asropudin (2013:6), Aplikasi adalah software yang dibuat oleh suatu perusahaan komputer untuk mengerjakan tugas-tugas tertentu. Dari pengertian tersebut dapat disimpulkan bahwa aplikasi adalah software atau alat terapan yang dibuat untuk mengerjakan tugas-tugas khusus dari pengguna. 
Aplikasi mobile adalah aplikasi yang berjalan pada perangkat mobile seperti smartphone. Aplikasi mobile mempunyai tugas atau fungsi tertentu pada mobile phone. Sistem aplikasi mobile memungkinkan user melakukan mobilitas dengan menggunakan perlengkapan seperti handphone. Mobile application juga dikenal sebagai aplikasi yang dapat diunduh dan memiliki fungsi tertentu sehingga menambah fungsionalitas dari perangkat mobile itu sendiri. Untuk mendapatkan mobile application yang diinginkan, User dapat mengunduhnya melalui situs tertentu sesuai dengan sistem operasi yang dimiliki.

\section{Teori Android}

Menurut Nasruddin Safaat H. (2012:1) android adalah sebuah sistem operasi pada handphone yang bersifat terbuka dan berbasis pada system operasi Linux. Android bisa digunakan oleh setiap orang yang ingin menggunakannya pada perangkat mereka. Android menyediakan platform terbuka bagi para pengembang untuk menciptakan aplikasi mereka sendiri yang akan digunakan untuk bermacam peranti bergerak. Android merupakan sistem operasi yang paling cepat mengupdate versinya dan merupakan sistem operasi hasil modifikasi kernel LINUX yang sudah terkenal di dunia komputer (Siregar, 2011:1). Dengan berbagai kemudahan yang ada pada android, menjadikan android cepat dikenal dan popular di kalangan pengguna mobile phone.

\section{Teori Graphical User Interface}

Graphical User Interface (GUI) adalah sebuah antar muka yang merupakan kumpulan teknik dan mekanisme untuk berinteraksi dengan sesuatu (Galitz, 2007). User interface dapat menerima informasi dari pengguna, dan memberikan informasi kepada pengguna yang bertujuan untuk membantu dalam mengarahkan alur navigasi sampai pengguna menemukan solusi masalah yang dicari. GUI harus berfokus kepada user bukan teknologi yang digunakannya, diawali dengan mengerti pengguna itu sendiri karena tujuan GUI adalah mempermudah pengguna, sehingga harus mengetahui siapakah pengguna dan bagaimana dengan karakteristiknya. Dengan begitu akan didapat rancangan GUI yang mempercepat pekerjaan pengguna itu sendiri. Pada saat merancang GUI, harus dibuat secara 
interaktif dan disertai dengan penjelasan fungsi-fungsi yang harus tertulis dengan jelas.

Fungsi harus diutamakan dibandingkan lapisan representasinya, karena jika fungsinya tak jalan maka hanya akan membuang waktu saja dalam membuat GUI. Penggunaan bahasa pun digunakan harus memikirkan dari sisi pengguna, tidak boleh membuat atau menggunakan bahasa yang hanya dimengerti oleh developernya sendiri.

Hal-hal yang perlu dipertimbangkan dan diterapkan pada saat mendesain user interface yang berfungsi dengan baik dan menarik adalah dalam hal bentuk, ukuran, nilai, warna, tata letak layout, icon sebagai navigasi dan typografi.

\section{METODE PENELITIAN}

Untuk mendapatkan data yang diperlukan guna menjawab permasalahan dilakukan sejumlah penelitian yaitu melalui: 1) Mengidentifikasi fenomena dan problematika; 2) Studi kompetitor dan studi komparator terhadap aplikasi sejenis. Studi kompetitor dilakukan terhadap aplikasi Android yang dimiliki Sekolah MDC dan SMA Ta'miriyah Surabaya. Sedangkan studi komparator adalah aplikasi Andorid Universitas Indonesia, Telkom University, dan Binus University; 3) Hasil wawancara dengan Kepala dan staf di Puslitbang PPPK Petra untuk mendapatkan data-data mengenai PPPK Petra dan untuk mengetahui inti permasalahan yang ada; 4) Observasi dan survei untuk mengamati tingkah laku pengguna dalam berinteraksi dengan gadget; 5) Studi literatur dan teori yang berhubungan dengan penelitian; 6) Hasil dari kuesioner untuk mengidentifikasi masalah.

\section{HASIL DAN PEMBAHASAN}

\section{Proses Perancangan dan Desain Final Media Utama}

Penentuan konsep perancangan aplikasi ini diperoleh dari keyword yang digali dari hasil fenomena, inti masalah, positioning dan target audiens. Sehingga diperoleh keyword yang sesuai yaitu "Simplicative" dari paduan kata simple dan Communicative. "Simplicative" memiliki arti sesuatu yang sederhana, mudah digunakan namun mempunyai fungsi yang informatif, sehingga pesan yang disampaikan dapat diterima dengan baik. Untuk mencapai hal itu, maka desain 
antar muka aplikasi ini akan dirancang dengan rapi dan sederhana sehingga sangat mudah untuk dioperasikan.

Aplikasi yang akan dirancang nantinya akan menggunakan nama "myPETRA". Dengan nama tersebut diharapkan user/penguna akan merasa memiliki kedekatan dan hubungan yang erat dengan PPPK Petra, sehingga aplikasi diharapkan dapat digunakan secara aktif dan berkelanjutan.

Proses perancangan media utama yaitu aplikasi mobile berbasis Android yang diawali dengan penentuan menu dan Use Case Diagram. Setelah itu dilakukan pembuatan sketsa untuk tampilan aplikasi. Tahapan dari proses desain adalah sketsa, digital, desain terpilih, hingga desain final. Berikut adalah proses perancangan:
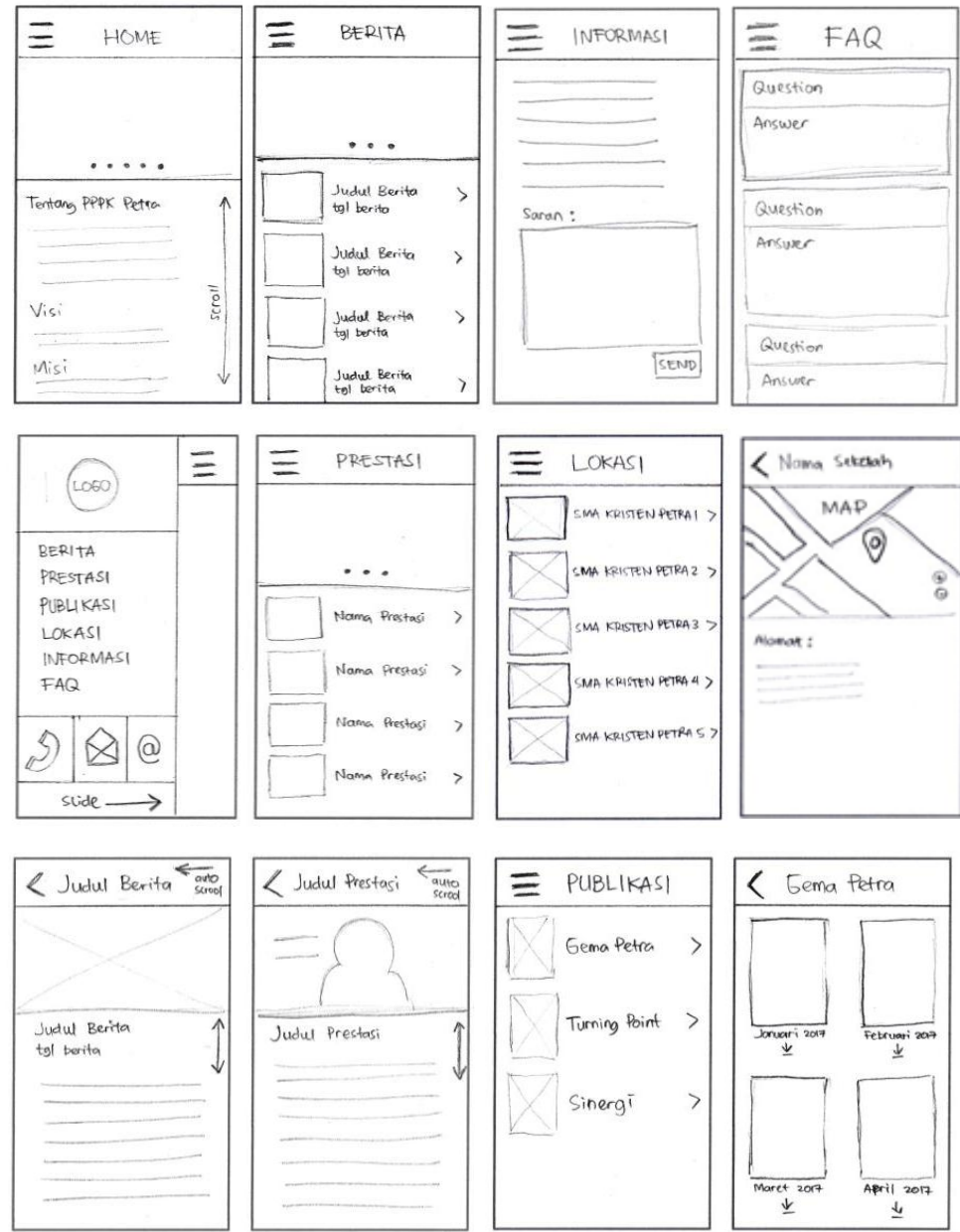

Gambar 1. Sketsa Layout

Sumber: Dokumentasi Penulis 
Dari hasil skestsa kemudian diproses menjadi desain digital yang disebut dengan istilah wireframe. Wireframe merupakan mockup atau rancangan awal sebuah desain applikasi yang dibuat secara digital menggunakan Adobe Photoshop dari hasil sketsa manual. Mockup merupakan gambar model atau prototype halaman secara full dan detail. Pada proses ini desain banyak mengalami revisi agar hasilnya sesuai dengan konsep dan tujuan perancangan. Berikut adalah hasil desain digital dan kumpulan desain final:
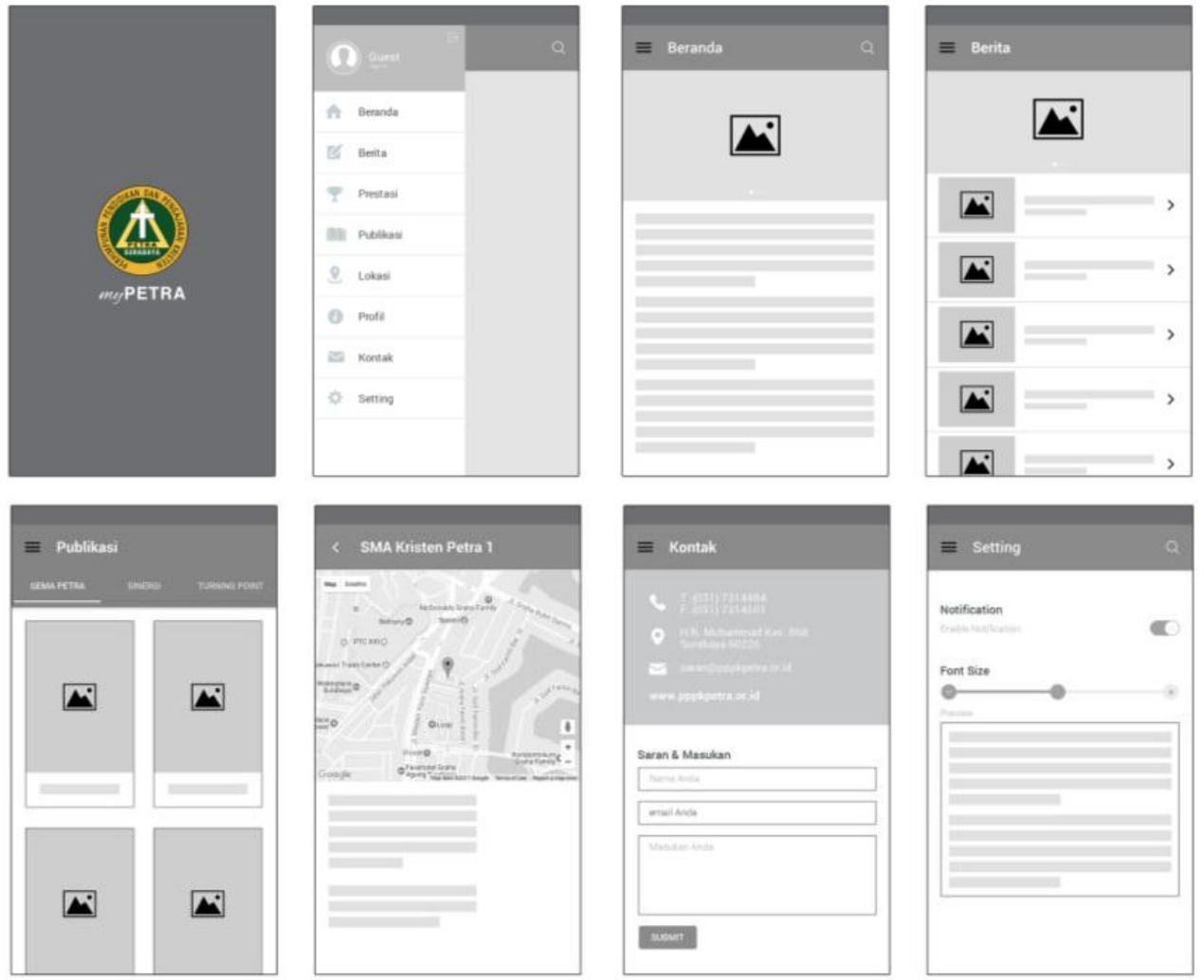

Gambar 2. Desain Layout Digital

Sumber: Dokumentasi Penulis 

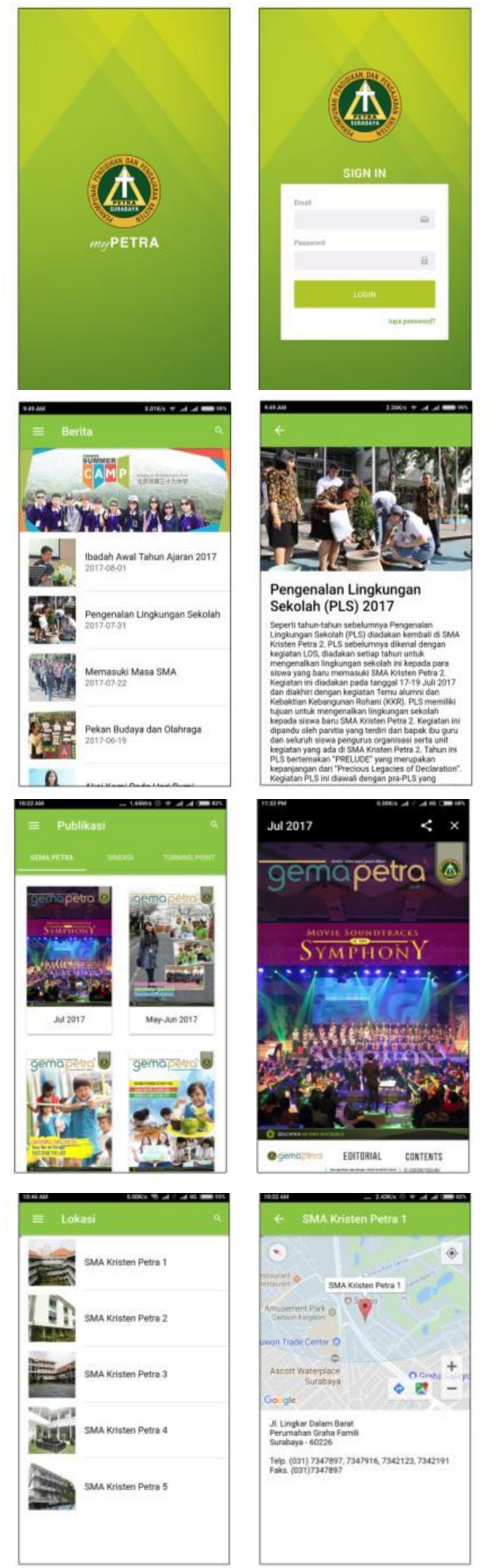
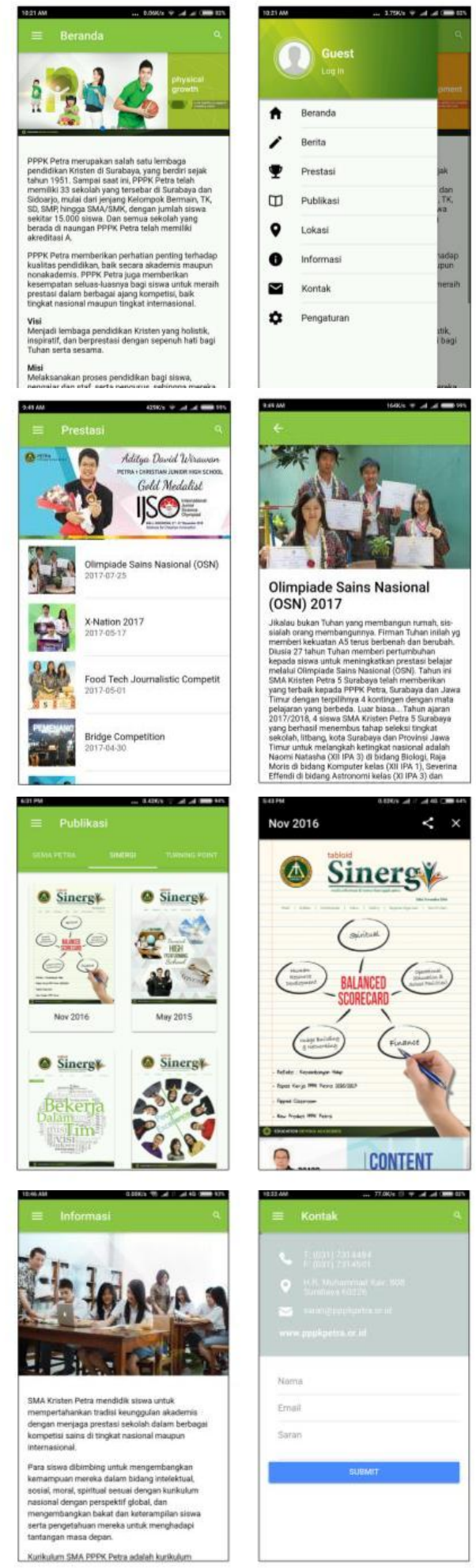

Gambar 3. Desain Final Media Utama

Sumber: Dokumentasi Penulis 


\section{Desain Final Media Pendukung}

Sebagai pelengkap perancangan aplikasi ini diperlukan media pendukung untuk mempromosikan produk aplikasi yang dibuat sehingga dapat membuat media utama diperkenalkan kepada siswa maupun diunduh secara luas untuk masyarakat umum. Media pelengkap yang akan dibuat meliputi Poster, X-Banner, Spanduk, Web Banner.
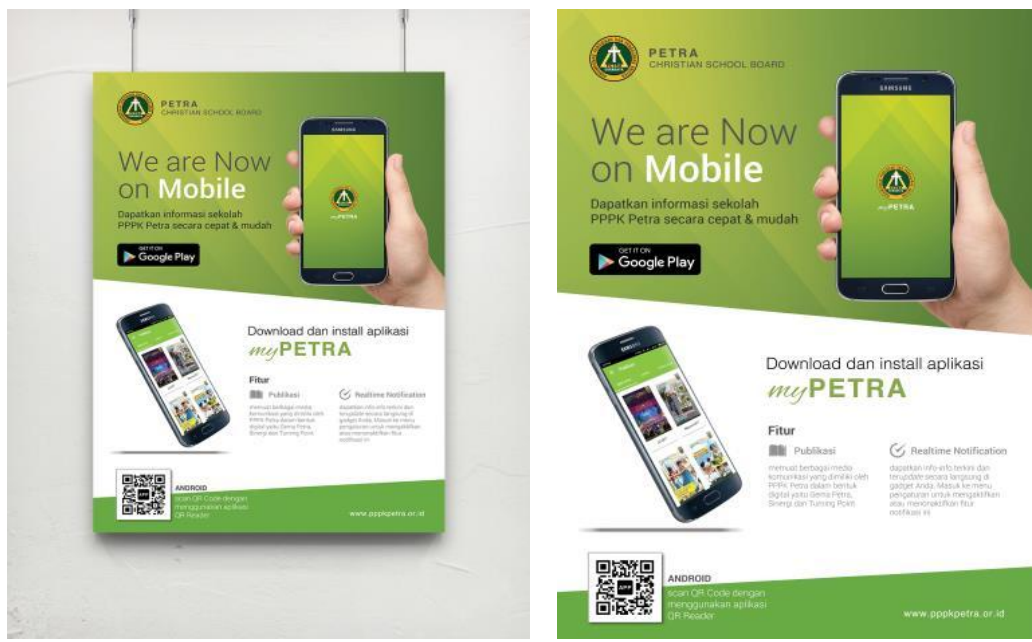

Gambar 4. Desain Final Poster

Sumber: Dokumentasi Penulis

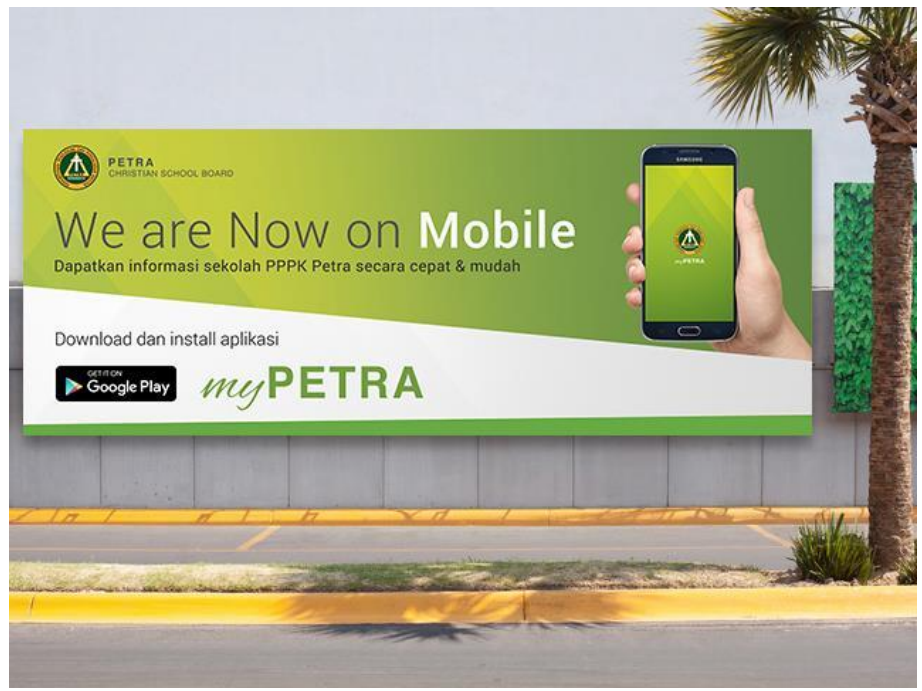

Gambar 5. Desain Final Spanduk

Sumber: Dokumentasi Penulis 

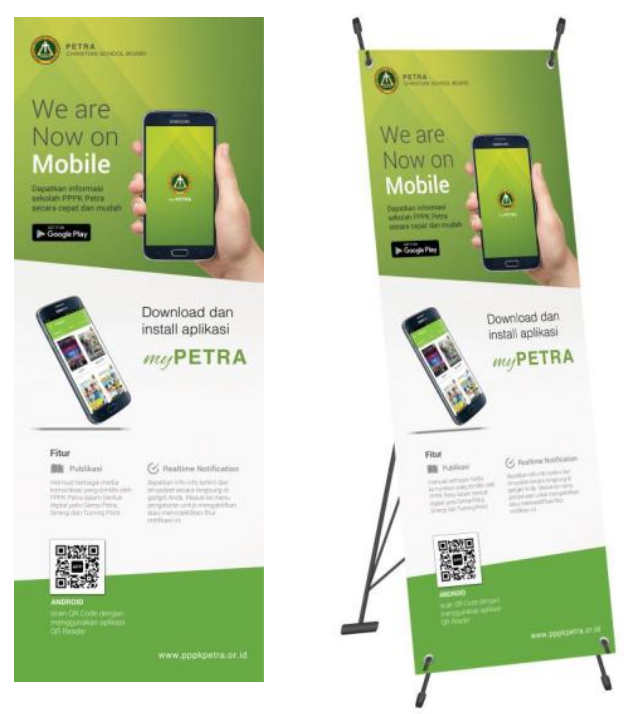

Gambar 6. Desain Final X-Banner

Sumber: Dokumentasi Penulis

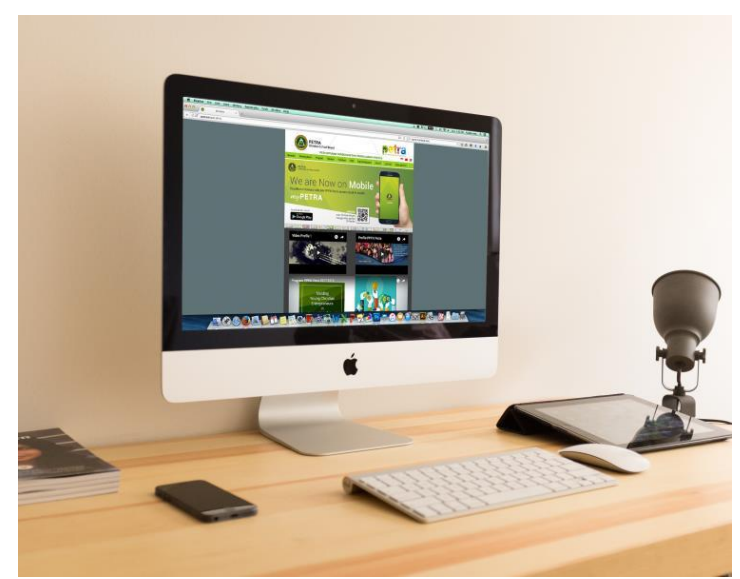

Gambar 7. Desain Final Web Banner

Sumber: Dokumentasi Penulis
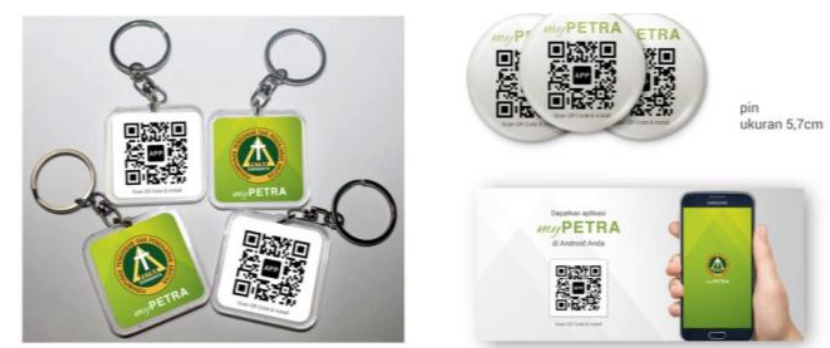

Gambar 8. Desain Final Media Pendukung Lain.

Sumber: Dokumentasi Penulis 


\section{SIMPULAN DAN SARAN}

\section{Simpulan}

Kemajuan teknologi hadir hampir di semua lini kehidupan manusia, termasuk dalam bidang pendidikan. Dunia pendidikan dituntut untuk terus-menerus mengikuti alur perkembangan ilmu dan teknologi yang kian berkembang pesat. Dalam penulisan tugas akhir ini, telah dilakukan analisis mengenai permasalahan yang terjadi di Sekolah PPPK Petra terutama pada media komunikasi dan informasi cetak. Berdasarkan hasil analisis tersebut maka dilakukan perancangan aplikasi myPETRA untuk smartphone Android. Kesimpulan yang didapat dari perancangan ini adalah sebagai berikut: a) Aplikasi mobile myPETRA dapat membantu siswa dan orangtua yang menginginkan informasi tentang sekolah secara lebih cepat dan mudah; b) Aplikasi yang dirancang cukup mudah digunakan oleh semua kalangan user yang menggunakan smartphone Android; c) Bagi sekolah PPPK Petra aplikasi ini dapat digunakan sebagai media komunikasi sekolah yang efisien dan mengurangi biaya cetak yang sangat tinggi; d) Perancangan media pendukung ke dalam berbagai media sangat diperlukan untuk mengenalkan dan mempromosikan aplikasi myPETRA kepada siswa dan orangtua.

Dari perancangan yang dilakukan, masih terdapat kekuranngan dan kendala yang dihadapi dalam aplikasi ini. Adapun kendala-kendala yang dihadapi antara lain: a) Keterbatasan waktu dalam melakukan penelitian terhadap pembuatan dan perancangan aplikasi media komunikasi; c) Penyesuaian waktu yang dimiliki antara penulis dengan pihak programmer; d) Pengalaman yang dimiliki oleh programer dalam mewujudkan desain tampilan aplikasi sesuai keinginan penulis; e) Keterbatasan jumlah smartphone yang bisa diuji selama tahap pengembangan aplikasi.

\section{Saran}

Dalam mendesain sebuah aplikasi mobile, penggunaan prinsip dasar desain seperti warna, layout dan grid sangatlah penting. Warna mempengaruhi nuansa dari aplikasi, layout dan grid berpengaruh dalam peletakan tombol dan tampilan lainnya. Ketiganya memerlukan pertimbangan lebih karena ukuran resolusi smartphone yang beragam dan tentunya berdampak pada ketiga unsur desain 
tersebut. Di samping hal tersebut, penulis juga menyadari bahwa dialog maupun diskusi dengan pembimbing, praktisi, dan orang-orang yang telah berpengalaman dalam bidang aplikasi dan desain sangat diperlukan untuk membuka wawasan dan pemikiran-pemikiran baru karena aplikasi bukan hanya dilihat dari desain saja, tapi termasuk perilaku dan kebiasaan seseorang yang diharapkan akan memakainya.

Saran-saran yang dapat menjadi pertimbangan dalam implementasi aplikasi ini agar berjalan sesuai dengan yang diharapkan adalah sebagai berikut: a) Pengaturan jadwal yang harus dikelola secara maksimal, agar perancangan dapat selesai tepat sesuai dengan yang dijadwalkan; b) Diperlukan seorang admin yang bertanggungjawab untuk mengontrol dan mengelola konten aplikasi; c) Mengembangkan fitur-fitur lain seperti promosi, nilai, materi pembelajaran, broadcast informasi, dan sebagainya sehingga semakin banyak pengunanya; f) Diharapkan aplikasi myPETRA dapat memperluas platformnya, tidak hanya Android tetapi juga iOS.

\section{DAFTAR PUSTAKA}

Asropudin, Pipin. 2013. Kamus Teknologi Informasi. Bandung: Titian Ilmu.

Galitz, Wilbert O. 2017. The Essential Guide to User Interface Design. Canada: Wiley Publishing,Inc.

Safaat, Nazruddin h. 2012. Pemrograman Aplikasi Mobile Smartphone dan Tablet PC berbasis android. Bandung: Penerbit Informatika Bandung.

Siregar, Ivan Michael. 2011. Membongkar source code berbagai Aplikasi Android. Yogyakarta: Gava Media.

Sutabri, Tata. 2012. Analisis Sistem Informasi. Yogyakarta: Andi. 